OPEN ACCESS

Edited by:

Wenhua Lu,

City University of New York,

United States

Reviewed by:

Mary Mitsdarffer,

Rutgers, The State University of New

Jersey, United States

Lei Xu,

East Carolina University, United States

*Correspondence:

Roman Koposov

roman.koposov@uit.no

Specialty section: This article was submitted to

Children and Health,

a section of the journal

Frontiers in Public Health

Received: 08 April 2021 Accepted: 29 June 2021

Published: 27 July 2021

Citation:

Koposov R, Isaksson J, Vermeiren $R$,

Schwab-Stone $M$, Stickley $A$ and

Ruchkin V (2021) Community Violence Exposure and School Functioning in Youth: Cross-Country and Gender

Perspectives.

Front. Public Health 9:692402. doi: 10.3389/fpubh.2021.692402

\section{Community Violence Exposure and School Functioning in Youth: Cross-Country and Gender Perspectives}

\author{
Roman Koposov ${ }^{1,2 \star}$, Johan Isaksson ${ }^{3}$, Robert Vermeiren ${ }^{4}$, Mary Schwab-Stone ${ }^{5}$, \\ Andrew Stickley ${ }^{6}$ and Vladislav Ruchkin ${ }^{3,5,7}$ \\ ${ }^{1}$ Regional Centre for Child and Youth Mental Health and Child Welfare, Faculty of Health Sciences, UiT The Arctic University \\ of Norway, Tromsø, Norway, ${ }^{2}$ Department of Epidemiology and Modern Technologies of Vaccination, Institute of Professional \\ Education, Sechenov First Moscow State Medical University, Moscow, Russia, ${ }^{3}$ Child and Adolescent Psychiatry Unit, \\ Department of Neuroscience, Uppsala University, Uppsala, Sweden, ${ }^{4}$ Leiden University Medical Center, Leiden, Netherlands, \\ ${ }^{5}$ School of Medicine, Yale University, New Haven, CT, United States, ${ }^{6}$ Stockholm Center for Health and Social Change, \\ Södertörn University, Stockholm, Sweden, ${ }^{7}$ Sater Forensic Psychiatric Clinic, Sater, Sweden
}

Background: Many children and adolescents experience violent events which can be associated with negative consequences for their development, mental health, school, and social functioning. However, findings between settings and on the role of gender have been inconsistent. This study aimed to investigate cross-country and gender differences in the relationship between community violence exposure (CVE) and school functioning in a sample of youths from three countries.

Methods: A self-report survey was conducted among school students (12-17 years old) in Belgium (Antwerp, $N=4,743$ ), Russia (Arkhangelsk, $N=2,823$ ), and the US (New Haven, $N=4,101$ ). Students were recruited from within classes that were randomly selected from within schools that had themselves been randomly selected (excepting New Haven, where all students were included). CVE was assessed with the Screening Survey of Exposure to Community Violence. School functioning was assessed with four measures: the Perceived Teacher Support scale, Negative Classroom Environment scale, and Academic Motivation and Perception of Safety at School scales. Multivariate Analyses of Covariance were performed to assess differences in the levels of school-related problem behaviors in boys and girls, who reported different degrees of CVE.

Results: Participants in all three countries reported a relatively high prevalence of violence exposure $36.2 \%$ in Belgium, $39.3 \%$ in Russia and $45.2 \%$ in the US who witnessed violence), with a higher proportion of girls than boys witnessing violent events (varied from 37.4 to $51.6 \%$ between the countries), whereas boys reported more episodes of victimization by violence than girls (varied from 32.3 to $49.9 \%$ between the countries). Youths who experienced increased CVE (from no exposure to witnessing to victimization) reported an increase in all school functioning problems in all of the countries and this association was not gender-specific.

Conclusions: Our findings suggest that regardless of differences in the level of CVE by country and gender, violence exposure is negatively associated with school 
functioning across countries. Nonetheless, even though reactions to community violence among adolescents may be expressed in a similar fashion, cross-country differences in social support systems should also be taken into account in order to provide culturally sensitive treatment modalities.

Keywords: violence, exposure, school functioning, gender, adolescents

\section{INTRODUCTION}

Community violence exposure (CVE) is usually defined as witnessing of, or victimization by a violence-related act within one's home, school, or neighborhood between individuals who are unrelated, and who may or may not know each other (1). Young populations represent a vulnerable group, with up to 1 billion children across the world being exposed to violence as both victims and witnesses annually (2). While the prevalence of CVE varies across settings and is for example, higher in the United States compared to many European countries $(3,4)$, the widespread nature of this phenomenon has led to it being increasingly recognized as a global public health problem (1).

Exposure to violent events can be extremely traumatic and lead to the development of severe physical, emotional or psychological problems (5). It has been linked both to clinical symptomatology and impairments in normal development, with negative consequences for mental health, substance use, social skills, relationships, and school functioning (6-10). Children with a history of violence exposure may differ from others in their developmental trajectories, often experiencing cognitive and emotional difficulties or behavioral problems, which in turn can impair their daily functioning, especially in demanding social settings, such as schools (11).

At the same time, findings regarding the impact of exposure to community violence on educational outcomes have been mixed. Although earlier studies reported no or weak relationships between community violence and academic achievement and social competence in school $(12,13)$, there is now growing evidence of an association between CVE and school functioning (14-17). In a nationally representative US sample of middle school students it was found that exposure to violence predicted decreased feelings of safety in school, which in turn was associated with lower student academic success (14). In another study it was similarly found that violent crime in the school neighborhood was associated with a decline in academic achievement among students (16).

In particular, it has been shown that children exposed to violence may have significant cognitive problems (e.g., attention and concentration difficulties, cognitive impairment), which negatively affect school functioning (18). Changes in cognitive function may contribute to poor performance on school assignments and tests (15). It also appears that a combination of violence exposure and subsequent symptoms of traumatic stress may create particular challenges for academic achievement $(19,20)$. For example, stress-related intrusive thoughts and fear of going to school may lead to increased absence from school and interfere with academic performance (15).
CVE is increasingly being evaluated in various settings and recently its cross-country aspects have also attracted attention (21-23). While some researchers postulate that the prevalence of post-traumatic stress may be consistent across different populations exposed to similar traumatic events, others argue that events considered as traumatic in the setting of one country may be differently perceived in another (24). Research assessing rates and consequences of CVE also suggests that exposure varies along several demographic characteristics and that estimates of the prevalence of CVE can differ even within a given country depending on such factors as gender and ethnicity $(25,26)$. Most studies report that males are more likely to encounter violent events (27), while females who experience trauma report more distress and impairment compared to traumatized males (28) and are more often diagnosed with post-traumatic stress disorder (29).

Findings on the prevalence rates of violence exposure-related trauma in Western industrialized countries have also been heterogeneous $(30,31)$, suggesting that different ethnic groups may be affected differently (32). African American youths more often witness and are victims of community violence than White youths $(33,34)$, even after controlling for demographic characteristics, such as age and gender (26). Youth exposure to community violence also varies by area of residence, with youths residing in economically disadvantaged areas $(34,35)$, urban areas (36), and high crime areas (37) being at greatest risk of exposure. Notably, the levels of psychosocial problems in exposed youths seem to correlate with the degree of exposure to violence $(38,39)$, where a greater degree of CVE (from no exposure to witnessing and to victimization) is associated with increased levels of post-traumatic stress and antisocial behavior $(23,40)$. Other studies have similarly indicated that in general, being directly victimized by violence is associated with a greater number of psychological problems that just witnessing violence (41). However, it remains unclear whether different levels of school functioning may similarly differ depending on the extent of CVE.

In summary, CVE is associated with a wide range of educational problems at school, but these relationships may vary by gender and between countries. The present article uses data from a large international study that collected information on CVE from culturally different samples, while also providing a gender perspective. Specifically, this study aims to: (1) assess the rates of CVE in three different countries and whether they differ by gender, and (2) explore whether a greater degree of exposure to community violence is associated with increasing problems in school-related functioning (further referred to as school functioning), whether such associations have a similar 
pattern in adolescents from different countries, and whether such patterns may be gender-specific. We hypothesize that boys from different countries will report higher rates of CVE than girls and that this gender difference will not be country specific. It is further hypothesized that an increasing degree of CVE will be associated with an increase in problems in school functioning, that this association may differ for boys and girls, but the patterns of these associations will nevertheless be generalizable across different countries.

\section{MATERIALS AND METHODS}

\section{Participants and Procedure}

Data in this study were drawn from the original Social and Health Assessment (SAHA) study conducted in Belgium, Russia, and the United States (US) in 2003-2004. The primary aim of this study was to determine the factors associated with adolescent health and well-being. The study sites were the following: Belgium [the city of Antwerp (population 523,000)], Russia [the city of Arkhangelsk (population 360,000)]; and the US [the city of New Haven, Connecticut (population 125,000)]. Details of the survey and its methodology have been previously published elsewhere (42). In brief, in the Belgian and Russian locations, data were collected from a representative sample of students aged 12-18 and 12-17, respectively, in the city's public schools. The participating schools were randomly selected from a list of all schools that represented different administrative school systems and different levels of education. To obtain a representative sample of the adolescent population, a two-stage selection procedure was used, with school buildings and classes used as the units of randomization. In the US, all students aged 12-17 who were in the public school system were included. Students were recruited from within classes that were randomly selected from within schools that had themselves been randomly selected. In all countries, students completed the survey in their classrooms during a normal school day. Written informed consent was obtained from all participants prior to the survey being administered, and both parents (on behalf of their children) and children could refuse to participate. Response rates for these surveys were high with only $3.6 \%$ of children refusing to participate in Russia, $<5 \%$ in Belgium and $<1 \%$ in the US. For comparability, the present study was limited to adolescents aged 12-17 years old with the analytical sample thus comprising 4,743 adolescents from Belgium, 2,823 from Russia, and 4,101 from the US.

Ethical approval for the study was obtained from the Northern State Medical University in Arkhangelsk (Russia), Yale School of Medicine (US), and the University of Antwerp (Belgium).

\section{Measures}

\section{Witnessing and Victimization}

Items assessing witnessed violence and violent victimization were derived from the Screening Survey of Exposure to Community Violence, developed by Richters and Martinez (43). The students were asked "about things that may happen to people in some neighborhoods." They used a 5-point scale response format [ranging from "None" (0) to "10 or more times" (4)] to describe whether in the past year they had witnessed or been a victim of any of six types of violence (been threatened with serious physical harm, beaten up or mugged, shot or shot at with a gun, attacked or stabbed with a knife, chased by gangs or individuals, or seriously wounded in an incident of violence). Three groups were formed based on the reported degree of exposure. Those who did not witness or experience any episodes of violence were considered as the non-exposed group. Those who reported at least one episode of witnessing violence, but no episodes of violent victimization were considered as the witnessing group. Finally, those who reported at least one episode of victimization were considered the victimization group.

School environment and academic motivation were assessed with four measures. All of the measures had a similar format, with the respondents being asked to report on the truth of a number of statements using a 4-point scale (with response options ranging from definitely not true to definitely true).

Seven items were used to assess Perceived Teacher Support in school: (i) teachers show concern when I am absent from school; (ii) teachers are willing to help students; (iii) most of my teachers notice when I am doing a good job and let me know about it; (iv) teachers are patient when students have trouble learning; (v) teachers don't often take time to give individual attention (reversed); (vi) my teachers are unfair (reversed); (vii) I like most of my teachers this year. These items were adapted from Hawkins et al. (44), developed by the creators of the survey (42), with higher scores indicating the perception of greater teacher support. Cronbach's alpha for the scale was 0.74 for Belgium, 0.72 for Russia and 0.73 for the US.

The Negative Classroom Environment scale also consisted of seven items: (i) students spend a lot of class time just talking to each other; (ii) teachers spend a lot of time in class trying to get students to behave; (iii) there is a lot of fighting between students in or around the school; (iv) students don't do what the teacher has told them to do; (v) students are often late for class; (vi) students criticize or joke about teachers a lot; (vii) teachers often shout at students. These items were adapted from Kasen et al. (45), with higher scores indicating a more negative perception of the classroom environment. Cronbach's alpha for the scale was 0.71 for Belgium, 0.72 for Russia, and 0.80 for the US.

The Academic Motivation scale was used to assess the perceived importance of academic achievements and academic motivation. It contains six items: (i) it is important to me to get at least a $\mathrm{B}$ average this year; (ii) it is important to me to be considered a bright student by my teachers; (iii) it is important to me to be thought of as a good student by the other students; (iv) I try hard at school; (v) education is so important that it's worth it to put up with things I don't like; (vi) I can't wait to quit school (reversed). These items were adapted from Jessor et al. (46) and Hawkins et al. (44), with higher scores indicating increased academic motivation. Cronbach's alpha for the scale was 0.69 for Belgium, 0.67 for Russia and 0.68 for the US.

Perception of Safety at School was assessed with five items developed by Weissberg et al. (47), e.g., "I feel safe on the school bus or while walking to school"; "I feel safe standing in front of my school building"; and "I feel safe at after-school activities at my school." Higher scores indicate a greater perception of safety 
at school. Cronbach's alpha for the scale was 0.77 for Belgium, 0.85 for Russia, and 0.82 for the US.

All of the measures used in the current study were validated in the US, including the CVE measures, and had also been used extensively in other settings internationally, including the countries included in our study $(23,48-51)$.

\section{Statistical Analyses}

Data were analyzed using the Statistical Package for the Social Sciences (SPSS-23.0). Multivariate Analyses of Covariance (MANCOVA) were performed to assess differences in the levels of school-related problem behaviors in boys and girls, who reported different degrees of exposure to community violence (no exposure, witnessing, and victimization). Hence, we used a 3 (degree of CVE) $\times 3$ (country) $\times 2$ (gender) design for the school functioning scales. Because both exposure to violence and school functioning may vary depending on the age of the responders, all analyses were conducted while controlling for age. The level of statistical significance for the study was $p<0.05$.

\section{RESULTS}

Table 1 shows the prevalence of violence exposure by gender in Belgium, Russia and the US. Students from each of the countries reported relatively high levels of exposure to community violence, with a higher proportion of girls than boys reporting witnessing violent events, whereas boys were more often victims of violence than girls (Table 1).

Table 2 presents the descriptive statistics (M, SD) from the MANCOVA on the perceptions of school functioning in relation to the degree of CVE for boys and girls in Belgium, Russia and the US. Compared to girls, in all of the countries boys with a similar degree of exposure generally perceived a lower level of teacher support, and reported lower academic motivation and school safety (except for in the US where girls reported lower safety at school). Subjects' scores varied on the negative classroom environment variable between the country and sex groups (Table 2).

Table 3 presents effect sizes for each dependent variable. The main effect for the type of exposure for the total group was significant [Wilks' lambda $=0.948 ; F_{(8,18,756)}=63.95, p<0.000$, $\left.\eta^{2}=0.027\right]$, with an increasingly negative perception of the classroom environment and decreasing academic motivation, perception of school safety and teacher support seen with an increasing degree of CVE (from no exposure to witnessing to direct victimization). The main effect for Gender was significant [Wilks' lambda $=0.992 ; F_{(4,9378)}=18.33, p<0.000, \eta^{2}=$ 0.008], demonstrating a difference in the perception of the school environment with boys describing it more negatively than girls. The main effect for Country was significant [Wilks' lambda $\left.=0.781 ; F_{(8,18,756)}=309.24, p<0.001, \eta^{2}=0.117\right]$, suggesting differences in the school variables between students in Belgium, Russia and the US. Students from the US had the highest negative perception of the classroom environment, academic motivation and teacher support and lowest school safety; students from Russia had the highest school safety and lowest teacher support scores; students from Belgium reported the least negative perception of the classroom environment and academic motivation. Finally, the main effect for Age was also significant [Wilks' lambda $=0.960 ; F_{(4,9,378)}=96.65, p<0.001$, $\left.\eta^{2}=0.040\right]$, with an increasingly negative perception of the classroom environment, decreasing academic motivation, poorer perception of school safety and teacher support with increasing age. The interaction effect for the Degree of CVE $\times$ Country was weakly significant [Wilks' lambda $=0.996 ; F_{(16,28,650)}=$ 2.39, $p<0.01, \eta^{2}=0.001$ ], indicating some differences in school functioning in relation to the degree of violence exposure between the countries. Specifically, while students from the US had a more negative perception of the classroom environment which increased from no exposure to victimization, students from Russia reported higher school safety which decreased from no exposure to victimization. The tests of between-subjects effects showed that there were weak differences related to the perception of school safety and negative classroom environment, whereas for the other school variables there were similar patterns between the countries in relation to an increasing degree of CVE. The interaction effect for Gender $\times$ Country was significant [Wilks' lambda $=0.995 ; F_{(8,18,756)}=5.78, p<0.001, \eta^{2}=$ 0.002 ], suggesting that gender differences in the perception of the school variables followed different patterns in different countries. Compared to boys, girls in the US had a more negative perception of the classroom environment, higher academic motivation and lower teacher support and school safety; girls in Russia had a more negative perception of the classroom environment and higher academic motivation, teacher support, and school safety; girls in Belgium had a less negative perception of the classroom environment and higher academic motivation, teacher support, and school safety. The follow up between-subjects tests showed that these gender differences were significant for all of the school variables except academic motivation. The interaction effect for the Degree of CVE $\times$ Gender was significant [Wilks' lambda $\left.=0.995 ; F_{(8,18,756)}=2.04, p<0.05, \eta^{2}=0.001\right]$. The follow up between-subjects tests indicated that the significant effect was related to differences in the perception of the classroom environment with boys having a more negative perception in relation to increasing CVE than girls. Finally, the interaction effect for the Degree of CVE $\times$ Country $\times$ Gender [Wilks' lambda $=0.998 ; F_{(16,28,650)}=1.30$, ns, $\left.\eta^{2}=0.001\right]$ was not significant, indicating that the gender-specific patterns of school variables occurring in response to varying degrees of CVE were similar in all of the countries.

As the differences by CVE, country, and gender could have been masked as a result of simultaneously assessing all of the outcomes in one model, we further examined associations for each of the outcomes individually using UNIANCOVAs, in order to determine whether the patterns would hold. The results were essentially the same.

\section{DISCUSSION}

The purpose of this cross-sectional study was to assess the rates of CVE in different countries and whether they differ by gender. We also aimed to explore whether an increasing degree 
TABLE 1 | Within-country comparisons of community violence exposure by gender $[N(\%)]$.

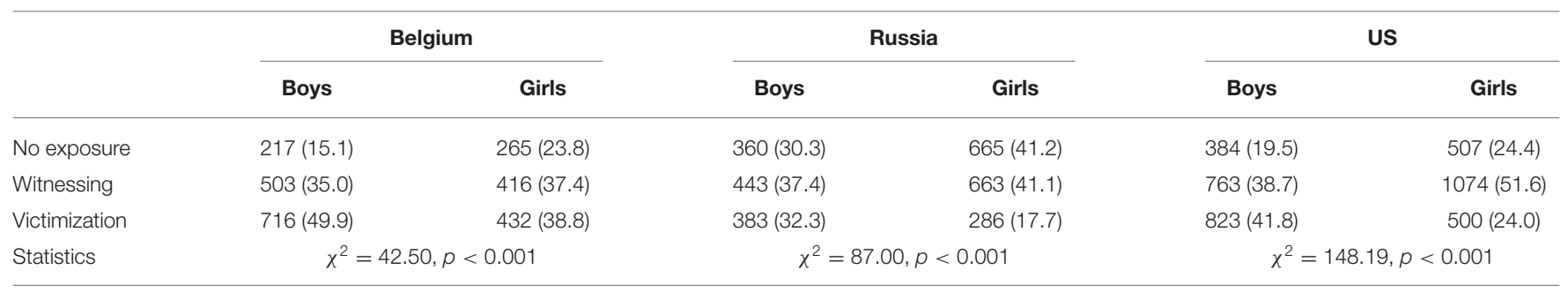

$\chi^{2}$, Chi-Square (the chi-square test).

$p$, Significance value.

TABLE 2 | Descriptive statistics of the school environment and academic motivation [M (SD)] in Belgium, Russia, and the US by degree of community violence exposure in boys $(B)$ and girls $(G)$.

\begin{tabular}{|c|c|c|c|c|c|}
\hline & & & \multicolumn{3}{|c|}{ Degree of community violence exposure } \\
\hline & & $G$ & $23.12(3.38)$ & $22.39(3.81)$ & $21.81(4.28)$ \\
\hline & Russia & $\mathrm{B}$ & $21.78(3.80)$ & $21.24(4.12)$ & $20.22(4.20)$ \\
\hline & & G & $21.97(3.97)$ & $21.16(4.13)$ & $20.78(4.11)$ \\
\hline & & G & $23.59(4.38)$ & $22.15(4.48)$ & $21.68(4.57)$ \\
\hline \multirow[t]{4}{*}{ Negative classroom environment } & Belgium & B & $16.20(3.84)$ & $17.70(3.94)$ & $18.40(3.87)$ \\
\hline & & G & $16.06(3.71)$ & $17.38(3.73)$ & $17.76(3.84)$ \\
\hline & Russia & B & $17.53(4.05)$ & $19.16(3.64)$ & $19.77(3.93)$ \\
\hline & & G & $18.62(3.31)$ & $19.31(3.73)$ & $19.52(3.47)$ \\
\hline & Russia & B & $17.55(2.91)$ & $17.05(2.98)$ & $16.34(3.26)$ \\
\hline & & G & $17.59(2.87)$ & $17.38(3.11)$ & $17.21(2.75)$ \\
\hline & US & B & $19.62(3.56)$ & $19.58(3.31)$ & $18.67(3.51)$ \\
\hline & & G & $20.64(2.87)$ & $20.03(3.01)$ & $19.16(3.58)$ \\
\hline \multirow[t]{6}{*}{ School safety } & Belgium & B & $17.48(4.05)$ & $17.00(4.36)$ & $16.24(4.25)$ \\
\hline & & G & $17.79(4.06)$ & $17.58(3.68)$ & 16.50 (3.95) \\
\hline & Russia & $\mathrm{B}$ & $18.54(4.05)$ & $18.38(4.69)$ & $16.97(4.69)$ \\
\hline & & $G$ & $18.81(4.16)$ & $18.79(4.13)$ & $17.18(4.84)$ \\
\hline & US & B & $17.94(4.26)$ & $17.15(4.42)$ & $16.06(4.58)$ \\
\hline & & G & $17.75(4.42)$ & $16.77(4.35)$ & $15.69(4.38)$ \\
\hline
\end{tabular}

The values presented are not adjusted for the list of covariates.

$M(S D)$, Mean (Standard Deviation).

US, United States.

of CVE in adolescents from different countries is associated with greater problems in different areas of school functioning and whether there may be certain patterns of associations, including gender-specific patterns that may be generalizable across different countries.

The overall findings showed that adolescents from each of the three countries reported a relatively high prevalence of exposure to community violence and that girls more often reported witnessing violence, while boys more often reported being victims of community violence. The proportion of youth in the current study who witnessed violence $36.2 \%$ in Belgium, $39.3 \%$ in Russia, and $45.2 \%$ in the US) was higher than reported in other studies. For example, according to a 2011 US victimization survey, $36.4 \%$ of 14 to 17 -year-old adolescents witnessed an assault in their community during the previous year (52). In another large-size study of 9 to 18 -year-old youths from seven European countries, 34\% reported experiencing at least one incident of community violence exposure during the past year 
TABLE 3 | Effect sizes for each dependent variable and summary statistics $\left(\eta^{2}, p\right)$.

\begin{tabular}{|c|c|c|c|c|}
\hline & Teacher support & Negative classroom environment & Academic motivation & School safety \\
\hline Age & $0.004,<0.001$ & $0.010,<0.001$ & $0.022,<0.001$ & $0.004,<0.001$ \\
\hline Violence exposure & $0.018,<0.001$ & $0.031,<0.001$ & $0.008,<0.001$ & $0.021,<0.001$ \\
\hline Country & $0.010,<0.001$ & $0.062,<0.001$ & $0.144,<0.001$ & $0.009,<0.001$ \\
\hline Gender & $0.001,<0.01$ & $0.001,<0.01$ & $0.006,<0.001$ & $0.000, \mathrm{~ns}$ \\
\hline Violence exposure $\times$ Country & $0.001, \mathrm{~ns}$ & $0.002,<0.01$ & $0.001, \mathrm{~ns}$ & $0.001,<0.05$ \\
\hline Violence exposure $\times$ Gender & $0.000, \mathrm{~ns}$ & $0.001,<0.01$ & $0.000, \mathrm{~ns}$ & $0.000, \mathrm{~ns}$ \\
\hline Gender $\times$ Country & $001,<0.05$ & $0.004,<0.001$ & $0.000, \mathrm{~ns}$ & $0.001,<0.01$ \\
\hline Violence exposure $\times$ Country $\times$ Gender & $0.000, \mathrm{~ns}$ & $0.001, \mathrm{~ns}$ & $0.001, \mathrm{~ns}$ & $0.000, \mathrm{~ns}$ \\
\hline
\end{tabular}

$\eta^{2}$, Eta-squared statistic.

p. Significance value.

ns, Non-significant.

(53). Our study results thus further underline that youth exposure to community violence is a global public health issue that warrants increased attention and action to protect the most vulnerable population groups.

The present cross-country study also sought to explore the relationship between an increasing degree of violence exposure and school functioning from country and gender perspectives. Overall, youths who experienced increased CVE (from no exposure to witnessing to victimization) reported an increase in a broad range of problems related to school functioning. This finding partly accords with the results of an earlier study that examined the relationship between exposure to community violence and academic functioning in a small sample of economically disadvantaged, African-American middle-school students, which found that exposure to community violence had only a weak relationship with academic functioning in general, but that the relationship was intensified under certain circumstances (54). Specifically, children who had very high achievement expectations and a very strong moral-religious emphasis were most at risk for poor academic functioning as exposure to community violence increased (54).

We also found that with a similar degree of exposure, boys (as compared to girls) in all of the countries generally perceived a lower level of teacher support, and reported lower academic motivation and school safety (except for in the US), while results were more mixed between country and gender groups for perceptions of a negative classroom environment. Our results suggest that while there may be country- and genderspecific differences in school functioning, and that increased problems in relation to an increasing degree of violence exposure may be gender-specific (with more problems related to school functioning among boys), the pattern of this gender-specific association was generalizable across different countries. From this perspective, these findings appear congruent with the notion found in the child trauma literature that there is a "universality of trauma responses" $(55,56)$. Accumulating evidence worldwide indicates that violence exposure can chronically and pervasively impact multiple developmental domains, including social, biological, psychological, and cognitive functioning, including academic outcomes $(57,58)$. Considering that failure in school can have long-term detrimental consequences for competency and social adjustment as adolescents transition into adulthood $(59,60)$, measures aimed at eradicating or reducing community violence may be beneficial in order to increase youth adjustment and ensure better social functioning in the future.

An extended discussion of the mechanisms linking CVE and school functioning is beyond the scope of the current paper although different factors might be involved. Some of the reported differences in the association between CVE and the perceived school environment may be related to an underlying comorbid psychopathology. In particular, previous research (11, 61) has shown that adolescents exposed to CVE may develop a number of mental health problems, which may impact on their school functioning. For example, depressed adolescents may perceive their teachers as being less supportive and have less academic motivation in general (50), while also perceiving the classroom environment as being more negative because of their decreased mood and a pessimistic perspective on life (62). Similarly, it is also possible that children with anxiety or posttraumatic stress symptoms/disorder (possibly resulting from community violence) may perceive their school environment as being less safe (63) as well as describe student-teacher relationships as poorer (64). Alternatively, it is possible that delinquency might play a role in this association. Specifically, earlier research has linked CVE to childhood delinquency (65). In terms of the current study this might be important as phenomena such as aggressive behavior and engaging in bullying have been, respectively, linked to lower levels of teacher support (66), and school safety (67), while a recent article has reported a relationship between problematic behaviors (disciplinary infractions) in school and a negative perception of the school environment (68). As yet, the exact factors linking CVE and delinquency are uncertain although some of the suggested potential mechanisms such as depression and anxiety (69) might also be important for school functioning as outlined above, which highlights the importance of prospective research to determine exactly how CVE is linked to school functioning and whether the relationship is direct or mediated by other variables.

Similar cross-country, and in some respects, gender nonspecific dynamics in school functioning in relation to the extent of community violence suggest that reactions to community violence among adolescents may be expressed in 
a similar detrimental fashion. Given this, the results of this study suggest that efforts aimed at reducing CVE may be important when it comes to improving school adjustment in adolescents. Decreasing the stress related to exposure to violence may potentially improve school engagement and academic motivation. Having said this, additional research is also warranted as before the notion that there are culturally invariant responses to trauma can be accepted, cross-country differences in social support systems should also be considered. Indeed, an enhanced understanding of CVE and the factors associated with it will further enable culturally sensitive treatment modalities to be provided if and where necessary (70).

The main strength of the current study includes the use of data from large adolescent community samples from three different countries with different ethnic backgrounds and varying levels of violence exposure. This study also has several limitations that should be mentioned. First, the use of a cross-sectional design prevented us from determining causality. Second, we relied on adolescent self-reports of CVE which may have been affected by different types of reporting bias e.g., social desirability bias. However prior studies have indicated that self-reports of behavior by adolescents tend to be valid and reliable $(71,72)$. Third, by including heterogeneous countries like the US, Belgium, and Russia together in the study, we cannot be certain that the CVEacademic functioning associations we observed are not due to other unmeasured variables, such as e.g., those associated with differences in race/ethnicity which were not considered in the study. At the same time, finding similar patterns of associations in all three countries, in spite of potentially unmeasured factors, suggest that the results were not country specific. Finally, reports on exposure to community violence were limited to the last year and therefore we were not able to identify children with longer histories of exposure to community violence.

\section{CONCLUSION}

In spite of the substantial differences in the rates of CVE between different countries, we found that girls more often witnessed

\section{REFERENCES}

1. Krug EG, Dahlberg LL, Zwi AB, Mercy JA, Lozano R. World Report on Violence and Health. Geneva: World Health Organization (2002).

2. World Health Organization, 2018. Violence Against Children. Available online at: https://www.who.int/news-room/fact-sheets/detail/violence-againstchildren (accessed April 08, 2021).

3. Hillis SD, Mercy JA, Amobi A, Kress H. Global prevalence of past-year violence against children: a systematic review and minimum estimates. Pediatrics. (2016) 137:e20154079. doi: 10.1542/peds.2015-4079

4. Mercy J, Krug EG, Dahlberg LL, Zwi AB. Violence and health: the United States in a global perspective. Am J Public Health. (2003) 93:25661. doi: 10.2105/ajph.93.2.256

5. McFarlane AC. The long-term costs of traumatic stress: intertwined physical and psychological consequences. World Psychiatry. (2010) 9:310. doi: 10.1002/j.2051-5545.2010.tb00254.x

6. Cooley-Strickland M, Quille TJ, Griffin RS, Stuart EA, Bradshaw CP, FurrHolden D. Community violence and youth: affect, behavior, violence, whereas boys tended to more often experience violent victimization. Our results further suggest that adolescents exposed to community violence may be at risk for a variety of problems in relation to school functioning and these associations seem to have a similar pattern in different countries, irrespective of gender. The results of this study suggest that efforts to reduce CVE may be important when it comes to improving school adjustment in adolescents.

\section{DATA AVAILABILITY STATEMENT}

The datasets used in this article are not readily available because the data cannot be shared publicly due to the initial decision of the local ethical committees, as well as the restrictions included in the informed consent statement (where it was stated that the data would only be used by the research group and would not be transferred elsewhere). Requests to access the datasets should be directed to Roman Koposov, roman.koposov@uit.no.

\section{ETHICS STATEMENT}

The studies involving human participants were reviewed and approved by the Ethics committee at the Northern State Medical University in Arkhangelsk (Russia), the Ethics committee at the Yale School of Medicine (US), and the Committee for Medical Ethics at the University of Antwerp in Belgium. Written informed consent to participate in this study was provided by the participants' legal guardian/next of kin.

\section{AUTHOR CONTRIBUTIONS}

VR, RK, JI, RV, MS-S, and AS were involved in the conceptualization and design of the study. RK and VR conducted the data collection and drafted the manuscript. VR conducted the data analysis. All authors reviewed and edited the manuscript. substance use, and academics. Clin Child Fam Psychol Rev. (2009) 12:127-56. doi: 10.1007/s10567-009-0051-6

7. Cuartas J, Leventhal T. Exposure to community violence and children's mental health: a quasi-experimental examination. Soc Sci Med. (2020) 246:112740. doi: 10.1016/j.socscimed.2019.112740

8. McLaughlin KA, Koenen KC, Hill ED, Petukhova M, Sampson NA, Zaslavsky AM, et al. Trauma exposure and posttraumatic stress disorder in a national sample of adolescents. J Am Acad Child Psy. (2013) 52:81530. doi: 10.1016/j.jaac.2013.05.011

9. Vermeiren R, Ruchkin V, Leckman PE, Deboutte D, Schwab-Stone M. Exposure to violence and suicide risk in adolescents: a community study. $J$ Abnorm Child Psychol. (2002) 30:529-37. doi: 10.1023/A:1019825132432

10. Vermeiren R, Schwab-Stone M, Leckman PE, Deboutte D, Ruchkin V. Violence exposure and substance abuse: findings from three countries. Pediatrics. (2003) 11:535-40. doi: 10.1542/peds.111.3.535

11. Perkins S, Graham-Bermann S. Violence exposure and the development of school-related functioning: mental health, neurocognition, and learning. Aggress Violent Behav. (2012) 17:89-98. doi: 10.1016/j.avb.2011.10.001 
12. Attar BK, Guerra NG, Tolan PH. Neighborhood disadvantage, stressful life events, and adjustment in urban elementary-school children. J Clin Child Psychol. (1994) 23:391-400. doi: 10.1207/s15374424jccp2304_5

13. Hill HM, Madhere S. Exposure to community violence and African American children: a multidimensional model of risks and resources. J Community Psychol. (1996) 24:26-43. doi: 10.1002/(SICI)15206629(199601)24:1<26:AID-JCOP3>3.0.CO;2-1

14. Patton DU, Woolley ME, Hong JS. Exposure to violence, student fear, and low academic achievement: African American males in the critical transition to high school. Child Youth Serv Rev. (2012) 34:38895. doi: 10.1016/j.childyouth.2011.11.009

15. Mathews T, Dempsey M, Overstreet $\mathrm{S}$. Effects of exposure to community violence on school functioning: the mediating role of posttraumatic stress symptoms. Behav Res Ther. (2009) 47:586-91. doi: 10.1016/j.brat.2009.04.001

16. McCoy DC, Roy AL, Sirkman GM. Neighborhood crime and school climate as predictors of elementary school academic quality: a cross-lagged panel analysis. Am J Commun Psychol. (2013) 52:128-40. doi: 10.1007/s10464-013-9583-5

17. Elsaesser C, Gorman-Smith D, Henry D, Schoeny M. The longitudinal relation between community violence exposure and academic engagement during adolescence: exploring families' protective role. J Interpers Violence. (2020) 35:3264-85. doi: 10.1177/0886260517708404

18. Bellair PE, McNulty TL. Cognitive skills, adolescent violence, and the moderating role of neighborhood disadvantage. Justice Q. (2010) 27:53859. doi: 10.1080/07418820903130823

19. Perfect MM, Turley MR, Carlson JS, Yohanna J, Gilles MPS. School-related outcomes of traumatic event exposure and traumatic stress symptoms in students: a systematic review of research from 1990 to 2015. School Ment Health. (2016) 8:7-43. doi: 10.1007/s12310-016-9175-2

20. Saltzman WR, Pynoos RS, Layne CM, Steinberg AM, Aisenberg E. Trauma- and grief-focused intervention for adolescents exposed to community violence: results of a school-based screening and group treatment protocol. Group Dyn Theory Res Pract. (2001) 5:291-303. doi: 10.1037/1089-2699.5.4.291

21. Kersten L, Vriends N, Steppan M Raschle NM, Praetzlich M, et al. Community violence exposure and conduct problems in children and adolescents with conduct disorder and healthy controls. Front Behav Neurosci. (2017) 11:219. doi: 10.3389/fnbeh.2017.00219

22. Löfving-Gupta S, Willebrand M, Koposov R, Blatný M, Hrdlička M, SchwabStone $\mathrm{M}$, et al. Community violence exposure and substance use: crosscultural and gender perspectives. Eur Child Adolesc Psychiatry. (2018) 27:493500. doi: 10.1007/s00787-017-1097

23. Schwab-Stone M, Koposov R, Vermeiren R, Ruchkin V. Cross-cultural findings on community violence exposure and internalizing psychopathology: comparing adolescents in the United States, Russia, and Belgium. Child Psychiatry Hum Dev. (2012) 44:516-24. doi: 10.1007/s10578-012-0344-8

24. Herbert JD, Forman EM. Cross-cultural perspectives on posttraumatic stress. In: Rosen GM, Frueh BC, editors. Clinician's Guide to Posttraumatic Stress Disorder. Hoboken, NJ: Wiley (2010). p. 235-61.

25. Schwab-Stone $M$, Chen C, Greenberger E, Silver D, Lichtman J, Voyce C. No safe haven II: the effects of violence exposure on urban youth. J Am Acad Child Adolesc Psychiatry. (1999) 38:359-67. doi: 10.1097/00004583-199904000-00007

26. Weist MD, Acosta OM, Youngstrom EA. Predictors of violence exposure among inner-city youth. J Clin Child Adolesc Psychol. (2001) 30:18798. doi: 10.1207/S15374424JCCP3002_6

27. Miller LS, Wasserman GA, Neugebauer R, Gorman-Smith D, Kamboukos D. Witnessed community violence and antisocial behavior in high-risk, urban boys. J Clin Child Adolesc Psychol. (1999) 28:2-11. doi: 10.1207/s15374424jccp2801_1

28. Foster JD, Kuperminc GP, Price AW. Gender differences in posttraumatic stress and related symptoms among inner-city minority youth exposed to community violence. J Youth Adolesc. (2004) 33:59-69. doi: 10.1023/A:1027386430859

29. Tolin DF, Foa EB. Sex differences in trauma and posttraumatic stress disorder: a quantitative review of 25 years of research. Psychol Bull. (2006) 132:95992. doi: 10.1037/0033-2909.132.6.959
30. Schafer JA, Huebner BM, Bynum T. Fear of crime and criminal victimization: gender-based contrasts. J Crim Justice. (2006) 34:285301. doi: 10.1016/j.jcrimjus.2006.03.003

31. Tagay S, Schlottbohm E, Reyes-Rodríguez ML, Repic N, Senf W. Eating disorders, trauma, PTSD, and psychosocial resources. J Eat Disord. (2014) 22:33-49. doi: 10.1080/10640266.2014.857517

32. Jenkins EJ, Bell CC. Violence among inner city high school students and posttraumatic stress disorder. In: Friedman S, editor. Anxiety Disorders in African Americans. New York, NY: Springer (1994). p. 76-8.

33. Sheats KJ, Irving SM, Mercy JA, Simon TR, Crosby AE, Ford DC. Violence-related disparities experienced by black youth and young adults: opportunities for prevention. Am J Prev Med. (2018) 55:462-69. doi: 10.1016/j.amepre.2018.05.017

34. Voisin DR, Bird JDP, Hardestry M, Shiu CS. African American adolescents living and coping with community violence on Chicago's southside. J Interpers Violence. (2011) 12:2483-98. doi: 10.1177/0886260510383029

35. Gaylord-Harden NK, Cunningham JA, Zelencik B. Effects of exposure to community violence on internalizing symptoms: does desensitization to violence occur in African American youth? J Abnorm Child Psychol. (2011) 39:711-9. doi: 10.1007/s10802-011-9510-x

36. Seal D, Nguyen A, Beyer K. Youth exposure to violence in an urban setting. Urban Stud. (2014) 2014:368047. doi: 10.1155/2014/368047

37. Reed E, Lawrence DA, Santana M, Welles CS, Horsburgh CR, Silverman $\mathrm{JG}$, et al. Adolescent experiences of violence and relation to violence perpetration beyond young adulthood among an urban sample of Black and African American males. J Urban Health. (2014) 91:96106. doi: $10.1007 / \mathrm{s} 11524-013-9805-\mathrm{z}$

38. Buka SL, Stichick TL, Birdthistle I, Earls FJ. Youth exposure to violence: prevalence, risks, and consequences. Am J Orthopsychiatry. (2001) 71:29810. doi: $10.1037 / 0002-9432.71 .3 .298$

39. Stansfeld SA, Rothon C, Das-Munshi J, Mathews C, Adams A, Clark $\mathrm{C}$, et al. Exposure to violence and mental health of adolescents: South African health and well-being study. BJPsych Open. (2017) 3:25764. doi: 10.1192/bjpo.bp.117.004861

40. Flannery D, Singer M, van Dulmen MHM, Kretschmar K, Belliston LM. Exposure to violence, mental health and violent behavior. In: Flannery DJ, Vazsonyi, AT, Waldman L, editors. The Cambridge Handbook of Violent Behavior and Aggression. Cambridge: Cambridge University Press (2007). p. 306-22.

41. Shields N, Fieseler C, Gross C, Hilburg M, Koechig N, Lynn R, et al. Comparing the effects of victimization, witnessed violence, hearing about violence, and violent behavior on young adults. J Appl Soc Sci. (2010) 4:7996. doi: $10.1177 / 193672441000400107$

42. Ruchkin V, Sukhodolsky DG, Vermeiren R, Koposov RA, Schwab-Stone M. Depressive symptoms and associated psychopathology in urban adolescents: a cross-cultural study of three countries. J Nerv Ment Dis. (2006) 194:10613. doi: 10.1097/01.nmd.0000198142.26754.18

43. Richters JE, Martinez P. The NIMH community violence project: I. Children as victims of and witnesses to violence. Psychiatry. (1993) 56:721. doi: $10.1080 / 00332747.1993 .11024617$

44. Hawkins JD, Catalano RF, Miller JY. Risk and protective factors for alcohol and other drug problems in adolescence and early adulthood: implications for substance abuse prevention. Psychol Bull. (1992) 112:64105. doi: 10.1037/0033-2909.112.1.64

45. Kasen S, Johnson J, Cohen P. The impact of school emotional climate on student psychopathology. J Abnorm Child Psychol. (1990) 18:16577. doi: 10.1007/BF00910728

46. Jessor R, Donovan JE, Costa F. Personality, perceived life chances, and adolescent health behavior. In: Lösel F, Hurrelmann K, editors. Health Hazards in Adolescence. Boulder, CO: Institute of Behavioral Science, University of Colorado, Walter De Gruyter (1990). p. 25-41.

47. Weissberg RP, Voyce CK, Kasprow WJ, Arthur MW, Shriver TP. The Social and Health Assessment. New Haven, CT: Zuthors (1991).

48. Henrich CC, Schwab-Stone M, Fanti K, Jones SM, Ruchkin V. The association of community violence exposure with middle school achievement: a prospective study. J Appl Dev Psychol. (2004) 25:327-48. doi: 10.1016/j.appdev.2004.04.004 
49. Karlsson E, Stickley A, Lindblad F, Schwab-Stone M, Henrich CC, Ruchkin V. Risk and protective factors for peer victimization: a 1-year follow-up study of urban American students. Eur Child Adolesc Psychiatry. (2014) 23:773-81. doi: 10.1007/s00787-013-0507-6

50. Elmelid A, Stickley A, Lindblad F, Schwab-Stone M, Henrich CC, Ruchkin V. Depressive symptoms, anxiety and academic motivation in youth: do schools and families make a difference? J Adolesc. (2015) 45:17482. doi: 10.1016/j.adolescence.2015.08.003

51. Isaksson J, Sukhodolsky DG, Koposov R, Stickley A, Ruchkin V. The role of gender in the associations among posttraumatic stress symptoms, anger, and aggression in Russian adolescents. J Trauma Stress. (2020) 33:55263. doi: $10.1002 /$ jts. 22502

52. Finkelhor D, Turner HA, Shattuck A, Hamby SL. Violence, crime, and abuse exposure in a national sample of children and youth: an update. JAMA Pediatr. (2013) 167:614-21. doi: 10.1001/jamapediatrics.2013.42

53. Kersten L, Fehlbaum L, Praetzlich M, Menks W, Steppan M, Mannstadt S, et al. Prevalence of community violence exposure and its effects on mental health problems in European adolescents. J Am Acad Child Adolesc Psychiatry. (2016) 55:S123. doi: 10.1016/j.jaac.2016.09.074

54. Overstreet $\mathrm{S}$, Braun S. A preliminary examination of the relationship between exposure to community violence and academic functioning. Sch Psychol Q. (1999) 14:380-96. doi: 10.1037/h0089015

55. Fletcher KE. Childhood posttraumatic stress disorder. In: Mash EJ, Barkley RA, editors. Child Psychopathology. New York, NY: Guilford (1997). p. 242-76.

56. Saigh PA, Yasik AE, Sack WH, Koplewicz HS. Child-adolescent posttraumatic stress disorder: prevalence, risk factors, and comorbidity. In: Saigh PA, Bremner JD, editors. Posttraumatic Stress Disorder: A Comprehensive Text. Needham Heights, MA: Allyn \& Bacon (1999). p. 18-43.

57. D'Andrea W, Ford J, Stolbach B, Spinazzola J, van der Kolk BA. Understanding interpersonal trauma in children: why we need a developmentally appropriate trauma diagnosis. Am J Orthopsychiatry. (2012) 82:187-200. doi: 10.1111/j.1939-0025.2012.01154.x

58. Spinazzola J, Ford JD, ZuckerM, van der Kolk BA, Silva S, Smith F, et al. Survey evaluates complex trauma exposure, outcome, and intervention among children and adolescents. Psychiatr Ann. (2005) 35:43339. doi: 10.3928/00485713-20050501-09

59. Loeber R. Development and risk factors of juvenile antisocial behavior and delinquency. Clin Psychol Rev. (1990) 10:141. doi: 10.1016/0272-7358(90)90105-J

60. Masten AS, Wright MO. Resilience over the lifespan: developmental perspectives on resistance, recovery, and transformation. In: Reich JW, Zautra AJ, Hall JS, editors. Handbook of Adult Resilience. New York, NY: The Guilford Press. (2010). p. 213-37.

61. McGill TM, Self-Brown SR, Lai BS, Cowart-Osborne M, Tiwari A, LeBlanc, et al. Effects of exposure to community violence and family violence on school functioning problems among urban youth: the potential mediating role of posttraumatic stress symptoms. Front Public Health. (2014) 2:8. doi: 10.3389/fpubh.2014.00008

62. Kuperminc GP, Leadbeater BJ, Emmons C, Blatt SJ. Perceived school climate and difficulties in the social adjustment of middle school students. Appl Dev Sci. (1997) 1:76-88. doi: 10.1207/s1532480xads0102_2

63. Fite PJ, Poquiz J, Díaz KI, Williford A, Tampke EC. Links between peer victimization, perceived school safety, and internalizing symptoms in middle childhood. Sch Psychol Rev. (2019) 48:30919. doi: 10.17105/SPR-2018-0092.V48-4

64. Sarkova M, Bacikova-Sleskova M, Madarasova Geckova A, Katreniakova Z, van den Heuvel WJA, van Dijk JP. Adolescents' psychological well-being and self-esteem in the context of relationships at school. Educ Res J. (2014) 56:367-78. doi: 10.1080/00131881.2014.965556

65. Patchin JW, Huebner BM, McCluskey JD, Varano SP, Bynum T.S. Exposure to community violence and childhood delinquency. Crime Delinq. (2006) 52:307-32. doi: 10.1177/0011128704267476

66. O'Connor KE, Hitti SA, Thompson EL, Farrell AD, Sullivan TN. Perceptions of school climate among subgroups of aggressive and victimized youth. School Ment Health. (2020) 12:169-81. doi: 10.1007/s12310-019-09343-z

67. Bradshaw CP, O’Brennan LM, Sawyer AL. Examining variation in attitudes toward aggressive retaliation and perceptions of safety among bullies, victims, and bully/victims. Prof Sch Couns. (2008) 12:10-21. doi: 10.5330/PSC.n.2010-12.10

68. Fefer SA, Gordon K. Exploring perceptions of school climate among secondary students with varying discipline infractions. Int J Sch Educ Psychol. (2020) 8:174-83. doi: 10.1080/21683603.2018.1541033

69. Hong JS, Huang H, Golden M, Patton DU, Washington T. Are community violence-exposed youth at risk of engaging in delinquent behavior? A review and implications for residential treatment research and practice. Resid Treat Child Youth. (2014) 31:266-83. doi: 10.1080/0886571X.2014.958343

70. Schwab-Stone M, Ruchkin V, Vermeiren R, Leckman P. Cultural considerations in the treatment of children and adolescents: operationalizing the importance of culture in treatment. Child Adolesc Psychiatr Clin N Am. (2001) 10:729-43. doi: 10.1016/s1056-4993(18)30027-0

71. Eckert TL, Dunn EK, Guiney KM, Codding RS. Self-reports: theory and research in using rating scale measures. In: Shapiro ES, Kratochwill TR, editors. Behavioral Assessment in Schools: Theory, Research, and Clinical Foundations. New York, NY: Guilford (2000). p. $288-322$.

72. Reynolds CR, Kamphaus, RW. BASC: Behavior Assessment System for Children: Manual. Circle Pines, MN, American Guidance Service (1992).

Conflict of Interest: The authors declare that the research was conducted in the absence of any commercial or financial relationships that could be construed as a potential conflict of interest.

Publisher's Note: All claims expressed in this article are solely those of the authors and do not necessarily represent those of their affiliated organizations, or those of the publisher, the editors and the reviewers. Any product that may be evaluated in this article, or claim that may be made by its manufacturer, is not guaranteed or endorsed by the publisher.

Copyright (c) 2021 Koposov, Isaksson, Vermeiren, Schwab-Stone, Stickley and Ruchkin. This is an open-access article distributed under the terms of the Creative Commons Attribution License (CC BY). The use, distribution or reproduction in other forums is permitted, provided the original author(s) and the copyright owner(s) are credited and that the original publication in this journal is cited, in accordance with accepted academic practice. No use, distribution or reproduction is permitted which does not comply with these terms. 